NORDISK MUSEOLOGI $1993 \cdot 1$, S. $61-65$

\title{
MUSEOLOGI OCH KULTURARV
}

\author{
Per-Uno Agren
}

I de länder - Tyskland, Frankrike och England - där museologin uppstått och utvecklats, kan de väldiga museikomplexen i Berlin, München, Paris och London förefalla tillräckliga som underlag for en särskild museivetenskap. När en sådan första gången nämns $i$ Sverige är det också av en tjänsteman vid det stora Nordiska Museet, Sune Ambrosiani. Men när begreppet tas upp internationellt, inom ICOM, av forreträdare för museiverksambeter av annat slag, med annan kulturbakgrund, andra sambällsforrutsättningar och med andra avsikter än de traditionellt europeiska, ifrägasätts snart museologins innehäll och definition. Traditionella museer och officiell monumentvaird ses som eurospecifika uttryck för ett sambälles hantering av sitt materiella kulturarv. Man söker efter mera generella formler så att museologibegreppet skall kunna täcka beskrivningen och analysen av många kulturers sätt att forbålla sig till materiella kvarlevor från det forrgångna. Museologins målsättning blir därmed att studera konstruktionen av det materiella kulturarvet genom olika kollektiva och individuella initiativ samt därur utvecklade institutioner och strukturer.

Museerna, kulturmiljövården och naturvården är en del av vårt samhälles offentlighet. Deras särart ligger i hävdandet och förmedlingen av nuvärdet $\mathrm{i}$ det materiella miljöarvet: den naturgivna och historiskt formade miljön, den levande naturen och de historiska objekten. Naturskydd och kulturvård gör det genom sin medverkan i resurshushållning och samhällsplanering, genom sin identifikation, vård och förmedling av värdefulla miljöer och miljökomplex. Museerna genom sin dokumentation, forskning och kunskapsförmedling om de föremål som blivit utvalda för bevarande. Främst är det deras samlingar och utställningar som i allmänna medvetandet ger museerna en identitet $i$ offentligheten.

Begreppet offentlighet har under senare år givits en ny innebörd. 'Offentligheten' är den arena för idéer och samhällsdebatt, där det offentliga samtalet pågår och utvecklas genom medier som tidningar, tidskrifter och andra litterära kanaler. I offentligheten sker den åsiktsbildning och attitydformning som ger samhällsutvecklingen dess dynamik. I den uppstår 'allmänna opinionen' och utkristalliseras den offentliga kulturen. 'Offentlighet' avser en verbal, abstrakt eller immateriell verklighet, som förmedlad av nya publikationsformer - blev central i den borgerliga kulturhegemonins Europa. Under 1900-talet utvidgas offent- 
PER-UNO $\AA$ GREN

62 ligheten genom tillkomsten av nya (mass) medier - radio, film, television, fonogram, videogram.

Före de, från upplysningstiden och framàt, utvecklade offentligheterna, fanns den representativa offentligheten, kyrkans och statsmaktens, den senare manifesterad i rättsväsen, skattemakt, krigsmakt och undervisningsväsen.

Alla dessa immateriella offentligheter hade också sina materiella motsvarigheter i kulturlandskap, bebyggelse och ting. Den materiella offentligheten är den ständigt närvarande, begränsande och disciplinerande ramen för det sociala livet. Den abstrakta offentligheten - det talade och lästa ordet, ceremonierna och beteendenormerna - är flyktiga och övergående, medan den materiella offentligheten är förblivande. Den transformeras kontinuerligt till det kulturarv som väljs, konserveras och förmedlas särskilt av kulturmiljövård, naturskydd och museer. Kulturvårdare och antikvarier opererar som mediatörer i gränsområdet mellan vetenskapernas och samhällsdebattens immateriella och den fysiska verklighetens materiella offentlighet.

Andra institutioner i offentligheten har sina vetenskaper - kyrkan har teologin, rättsväsendet juridiken, skolan pedagogiken, arkiven arkivistiken etc. På motsvarande sätt studerar museologin hur det historiska kulturarvet skapas i den materiella offentligheten, hur det definieras, skiljs ut och förvaltas av officiella organ och institutioner, men även av enskilda, grupper och organisationer. Det materiella kulturarvet som samhällsfenomen är - kort uttryckt museologins område. I kulturarvet inbegrips alltså även naturarvet, eftersom detta selekteras kulturellt. 'Arv' innebär att den materiella miljön får sin innebörd $\mathrm{i}$ en kumulativ historisk process genom användning, namngivning och vetenskapligt studium, ett arv som överförs från generation till generation av samhällsmedborgare.

Definitionen ter sig naturlig ur nordisk synpunkt. Naturminnen, liksom historiens materiella kvarlevor, antingen det rört sig om fornminnen, kulturlandskap, byggnader och byggnadsmiljöer eller föremål, hör ur samhällets bevarandesynpunkt samman. Dock har ansvaret för de skilda komponenterna, de fasta och de flyttbara, lagts på olika samhällsorgan och institutioner: naturvårdens och kulturmiljövårdens organ samt museiväsendet. I nu gällande svensk lagstiftning (från 1988) vidgas ansvaret i lagens portalparagraf:

"Det är en nationell angelägenhet att skydda och vårda vår kulturmiljö. Ansvaret för detta delas av alla."

Synen både på bevarandets mål och metoder för att lösa bevarandeuppgiften har utvecklats parallellt. Detta sedan 1600-talet fortlevande samband gör det naturligt att låta det materiella kultur- och naturarvet konstituera museologins forskningsområde, ett synsätt som dessutom, vilket redan antytts, alltmer gör sig gällande internationellt.

Naturen och historiens materiella lämningar studeras av många vetenskaper - så av museifolkets traditionella och ur museisamlingar födda discipliner: arkeologi, etnologi och konstvetenskap, vilkas forskning under lång tid varit samlingsrelaterad. Ett urval som anses värt att skydda och bevara görs av museer, naturskydd och kulturvård och transformeras därmed från bruksting till kunskapsting eller museala objekt (också naturminnen, fornlämningar och byggnadsminnen är alltså enligt detta synsätt museala objekt). Detta blir vårt 
bestående materiella kulturarv. Begreppet är socialt konstruerat och grundat på värderingar. Museologin studerar hur det museala objektet konstitueras, vilka värderingar och beslut som styr den museala processen från urval och insamling till visning och förmedling och därmed vilken historiebild, kulturuppfattning och natursyn som projiceras i skyddade objekt och miljöer: alltså människans forballande till sin fysiska omvärld som historia. Vilka värderingar har vid olika tidpunkter bestämt miljöarvets innehåll, vilken har dess - och därmed historiens och naturens - sociala funktion varit? Vilka värdeutsagor har knutits till bevarade miljöer, monument, naturföremål och artefakter? För en helhetsförståelse är museologin beroende av resultaten från många vetenskapers undersökningar och är på så sätt utpräglat tvärvetenskaplig.

Den museologiska kommunikationens särart är att göra meningar inte läsliga, utan synliga. Genom hela den museala processen - dokumentation, bevarande, förmedling är detta fundamentalt: kulturmiljö- och naturskydd, liksom museer har sin primära uppgift i det påtagliga och synliga, sitt mål i den visuellt förmedlade förståelsen av det materiella miljöarvets historiska innebörder och relation till nuet. Med denna förankring $\mathrm{i}$ det materiella/visuella skiljer sig museologin från det övriga humanistiska vetenskapssamhället, som har textproduktion som sitt viktigaste mål, även när 'verkligheten', inte uteslutande texter, är utgångspunkten.

Museologin har tre teoretiska huvudperspektiv: ett historiskt, som söker beskriva och förstå natur- och kulturarv vid en viss tid och på en viss plats; ett sociologiskt, som studerar de beteenden, verksamheter och institutioner som blivit en följd av föreställ- ningen om ett natur- och kulturarv; ett 63 kommunikativt, som gäller miljöarvets förmedling i tid och rum.

Dessa tre perspektiv kan tillämpas på kultur- och naturvårdens samt museernas principiellt likartade konkreta arbetsuppgifter inom den materiella miljöhistorien: urval, klassifikation, dokumentation, vård, konservering och förmedling.

Några exempel på museologiska forskningsuppgifter:

Bevarandeideologier som de framträder i urvals- och samlingshistoriska studier. Med sitt ursprung i representativa offentligheter, sin väldiga expansion $i$ den borgerliga offentligheten och nu som del av den kulturpolitiska offentligheten med ett växande samhällsekonomiskt stöd, har både miljövård och museer ett utifrån många värdesystem uppbyggt arv att förvalta. Många bevarandeobjekt har dessutom haft sitt ursprung i enskilda initiativ (och nya tillförs ständigt), vilket ytterligare komplicerar bilden. På det teoretiska planet gäller det att studera på vad sätt upplevelser och förväntningar investeras i den fysiska livsmiljöns element så att de får samhälleligt symbolvärde, d v s en innebörd som uppfattas och delās av många och därför tilldelas värden som motiverar kollektiva ekonomiska satsningar i bevarandeaktioner och bevarandeinstitutioner. Liksom för andra vetenskapers studium av institutioner, som förändrats och anpassats till nya samhällssituationer, är studiet av modifikationer och omtolkningar viktiga. Med en given historisk definition av miljöarvet, gäller det att identifiera den dokumentation som finns om miljöns och tingens innebörd och betydelse. Varför har man sagt sig: "Detta får inte gå förlorat!"? Vilka har kriterierna varit, hur har de redovisats? Överens- 
PER-UNO $\AA$ GREN

64 stämmer program och praxis? Uppgiften gäller även nutiden: hur definieras miljöarvet i de dokumentations- och bevarandeprogram som tillämpas av olika institutioner? Hur används forskning i arkeologi etc i den museologiska kontexten? Enbart storleksordningen i samhällssatsningarna och det intresse som besökstalen vid institutionerna speglar, gör att verksamhetens syften och mål inom denna offentlighet, liksom deras anknytning till och samspel med annan samhällsverksamhet, förtjänar studium och analys.

Dokumentationsteoretiska studier. Vilka variabler har bestämt dokumentationens uppbyggnad inom bevarandeinstitutioner, (vilken kunskap har samlats, hur har bearbetningen av dokumentationens data skett $\mathrm{i}$ förmedlingsfasen? Hur lagras dokumentationen så att miljöarvets autenticitet och tillförlitlighet som historiskt källmaterial säkras för samtida och framtida förmedling?

Förmedlingsstudier. Hur har historiens materiella närvaro förmedlats - nationellt, regionalt, lokalt? Hur tillgängliga har de historiska minnena varit i miljö och museer? Vilka historiebilder har presenterats? Vad har minnesmärken och museer betytt för historisk/kulturell traditionsöverföring? Vilka har förmedlingens aktörer och målgrupper varit? Hur sker förmedlingen idag, vad betyder historia och materiellt kulturarv i socialt liv?

Här har allmänt angivits några uppgifter för museologin. Från de övergripande teoretiska frågorna 'varför och vad samlar vi?', 'varför visar vi', 'vems kultur- och naturarv bygger vi upp, legitimerar och förmedlar? till de praktiska frågorna 'hur samlar och bevarar vi?, hur vårdar vi?, hur visar vi?. Vem nås av vår förmedling och hur framgångsrik är den? I centrum står hela tiden det materiella miljöarvet, det samhälle, de institutioner och människor som producerar och hanterar det.

Museologins område är globalt. Från studiet av det lokala kulturarvets konstruktion, vidgas perspektivet successivt till en regional, nationell, nordisk och europeisk nivå. Hur karakteriseras och avgränsas kulturarvets innehåll på dessa nivåer som en del av den offentliga kulturen? Hur ser det ut i jämförelse med ett österländskt, afrikanskt etc kulturarv?

Den museologiska forskningen måste framför allt söka sig ut till institutionerna själva och deras arkiv med kataloger, protokoll, skriftväxling, verksamhetsberättelser, dokumentation av utställningar och publikverksamhet. Vidare till deras utställningar och till de levande traditionsbärare som kan förmedla personliga minnen och erfarenheter, ge sina egna perspektiv. Det är här de viktigaste dokumentationsuppgifterna väntar.

Eftersom forskningen är särskilt beroende av studier regionalt och lokalt, ägnar sig forskningsuppgifterna i eminent grad för att bearbetas av antikvarierna och intendenterna själva, alltså i praktisk samverkan mellan museer och universitet.

Museologisk forskning erbjuder alltså uppgifter av många slag, där varje insats bidrar till att lägga grunden för ett kunskapsbygge som både kan förbättra underlaget för museologisk utbildning och komma museal och kulturvårdande praxis till godo. Bristen på facklitteratur, som belyser nordiska förhållanden, redovisar och analyserar erfarenheter av miljövårdande och musealt arbete, är påtaglig och accentueras av att planer på en länge efterfrågad fortoch vidareutbildning nu aktualiserats. 


\section{SUMMARY}

\section{Museums and Cultural Heritage}

The literal and original meaning of the term museology - science of museums - was connected with the practices of the big museums in the continent of Europe. The term was used to cover the different methods applied in museum work. In recent years the concept has been expanded as a result of the continuos debate going on within ICOM (The International Council of Museums). Museology, it is argued, should study how, in different cultures and societies, people select and treat their material heritage, the movable property as well the physical environment, and what type of institutions and structures are established to manage the preservation, care and communication of the historical heritage. Such a definition of museology is easy to accept and adopt in Scandinavia, where historically there has been a close connection between the State Board of Antiquities responsible for the care of monuments and sites, on the one hand and the public museums on the other. Then the paper states that the relationship between material and non-material culture, which are both present in public discourse, constantly presents tensions - the one being static and permanent, the other dynamic and transient. In museology the study of the museological process, wherein the cultural heritage of a society is created through the interaction of the non-material and the material elements of culture, is of central concern. The second basic concept is the museological object - how it is selected and defined in different societies over time. Museology has three main theoretical perspectives - a historical one which describes and explains the cultural heritage in different places and times, a sociological one which studies the behaviour, activities and institutions which the idea of cultural heritage has produced, and a communicative one which studies the way in which the heritage has been passed on in different societies. Finally the paper exemplifies the type of rese arch which should be carried out by museologists in the fields of theory of documentation, preservation and communication. The necessity for an interdisciplinary basis for museology is stressed throughout the paper.

Per-Uno Agren är högskolelektor och prefekt vid institutionen for museologi, Umeà universitet. Arbetade åren 1953-83 vid Västerbottens museum, Umeå (Adr: Institutionen for museologi, Umea Universitet, S-901 87 Umeå). 